\title{
PROJEÇÕES DE CONSUMO DE MADEIRA COM FINS ENERGÉTICOS PARA SECAGEM DE GRÃOS NA REGIÃO DE GUARAPUAVA, PR
}

\author{
André Ramos Dresch ${ }^{1}$, Vitor Afonso Hoeflich², Romano Timofeiczyk Júnior ${ }^{3}$, Erich Gomes Schaitza ${ }^{4}$ \\ ${ }^{1}$ Eng. Florestal, M.Sc., UFPR, Curitiba, Paraná, Brasil - andredresch@ hotmail.com \\ ${ }^{2}$ Eng. Agrônomo, Dr., Depto. Economia e Política Florestal, UFPR, Curitiba, Paraná, Brasil - vitor.ufpr@ gmail.com \\ ${ }^{3}$ Eng. Florestal, Dr., Depto. Economia e Política Florestal, UFPR, Curitiba, Paraná, Brasil - romano.timo@gmail.com \\ ${ }^{4}$ Eng. Florestal, Embrapa Florestas, Colombo, Paraná, Brasil - erich.schaitza@embrapa.br \\ Recebido para publicação: 28/03/2012 - Aceito para publicação: 15/10/2013
}

\begin{abstract}
Resumo
O objetivo principal deste artigo foi avaliar a capacidade potencial da indústria madeireira em atender às necessidades da secagem dos grãos produzidos na região de Guarapuava em florestas plantadas de eucalipto voltadas à produção de energia a partir de sua biomassa. Sob a ótica metodológica, a pesquisa caracterizou-se pela natureza aplicada, enfoque quantitativo e caráter explicativo e por estar fundamentada nos princípios de cadeias produtivas e de demanda derivada. Os resultados indicaram que normalmente os plantios energéticos de eucalipto na região apresentam produtividade de $40 \mathrm{~m}$ /ha/ano. Os grãos de milho, soja, trigo e cevada passam por processos de secagem na região. Utiliza-se $0,0574 \mathrm{~m}^{3}$ de madeira de eucalipto para secar uma tonelada de milho, $0,0218 \mathrm{~m}^{3}$ por tonelada de soja, $0,0224 \mathrm{~m}^{3}$ por tonelada de trigo e $0,0258 \mathrm{~m}^{3}$ por tonelada de cevada. Estimou-se que, entre os anos de 2012 e 2022, a área total necessária para atender a secagem desses grãos pode variar entre 1.947 e 4.800 ha, com média entre 177 ha e 436,4 ha, conforme o cenário analisado. Os resultados indicam a necessidade da integração dos plantios florestais de eucalipto às cadeias produtivas agrícolas, visando ao atendimento das necessidades de secagem de grãos da região.

Palavras-chave: Produção florestal; energia da biomassa; secagem de grãos.
\end{abstract}

\begin{abstract}
Projections of wood consumption for energy purposes of grain drying in the region of Guarapuava$P R$. The main aim of this work was to evaluate the potential capacity of the wood industry to cater the grain drying facilities in the region of Guarapuava, based on areas of eucalyptus plantations aimed at producing wood for energy purposes. Methodologically, this research is characterized by its applied nature, quantitative focus and explanatory character; it is also based on the principles of derived demand and supply chains. The results indicated that eucalyptus plantations for energy purposes in the region have produced $40 \mathrm{~m}^{3} / \mathrm{ha}$ of wood per year. The grains of maize, soybeans, wheat and barley are dried in grain dryers in the region. In general, the drying process uses $0.0574 \mathrm{~m}^{3}$ of eucalyptus to dry one ton of maize, $0.0218 \mathrm{~m}^{3}$ per ton of soybeans, $0.0224 \mathrm{~m}^{3}$ per ton of wheat, and $0.0258 \mathrm{~m}^{3}$ per ton of barley. Between years 2012 to 2022 the total area required to meet the drying of grains can vary between 1946.7 and 4799.9 ha, an average of 177 to 436.4 ha, depending on the scenario. It is important to integrate the eucalyptus plantations to the agricultural production chain seeking to meet the needs of grain drying in the region.

Keywords: Guarapuava region; wood for energy purposes; eucalyptus forests.
\end{abstract}

\section{INTRODUÇÃO}

O setor florestal é composto por um conjunto de atividades econômicas complexas e diversificada que tem contribuído efetivamente para o crescimento e desenvolvimento socioeconômico do Estado do Paraná e do Brasil, através da geração de renda, tributos, divisas, empregos diretos e indiretos e preservação do meio ambiente (BUAINAIN; BATALHA, 2007; BITTENCOURT; OLIVEIRA, 2009). 
No Paraná, a atividade florestal representou um dos ciclos econômicos mais importantes do estado, com a exploração e uso da Araucaria angustifolia (Bertol.) Kuntze 1898 (BITTENCOURT; OLIVEIRA, 2009). Em termos econômicos, dos 44,3 bilhões de reais do Valor Bruto da Produção (VBP) paranaense de 2010, cerca de 7\% correspondem aos produtos florestais (GODINHO, 2011). Socialmente, estima-se que as atividades associadas à produção e ao processamento de madeira tenham gerado 150 mil empregos diretos e mais de 600 mil indiretos no ano de 2008 em todo o estado (POLZL, 2011).

$\mathrm{Na}$ região de Guarapuava, o setor madeireiro durante anos foi o principal gerador de renda, e em 2008, aproximadamente $75 \%$ dos empregos gerados na indústria correspondiam à cadeia produtiva da madeira (NOVAKOVSKI; FAJARDO, 2008). No município de Guarapuava, Ribas (2009) identifica que a indústria da madeira tem forte influência sobre a economia local.

Do ponto de vista ambiental, a atividade florestal contribui para a conservação da natureza, promoção da biodiversidade, recuperação de áreas degradadas, manutenção dos regimes hídricos e manutenção da qualidade do ar e da água. As contribuições dessa atividade para a sociedade são várias, entre as quais se destaca a de fornecimento energético. Segundo Brasil (2008), a madeira tem sido uma tradicional e importante matéria-prima para a produção de energia. Além disso, é uma das fontes renováveis de energia com maior potencial de crescimento (BRASIL, 2005).

Segundo Teixeira (2009), para o Paraná existe a expectativa de que a procura por madeira com fins energéticos aumente em função do crescimento dos setores primário e secundário. Além disso, Mendes Júnior et al. (2011) lembram que, no Paraná, muitos dos produtos agrícolas, como soja e milho, passam por um processo de secagem, visando o beneficiamento ou armazenamento, e que o principal combustível utilizado é a madeira.

Em função do impacto social, econômico e ambiental da atividade florestal, da importância da madeira como combustível para os processos de secagem de grãos e da forte presença da indústria agrícola na região de Guarapuava, formula-se o seguinte questionamento: qual é a área potencial de florestas plantadas de eucalipto com fins de produção de madeira energética na região de Guarapuava necessária abastecer os processos de secagem de grãos que ocorrem nessa região?

Nesse contexto, o objetivo principal do estudo foi avaliar a capacidade potencial da indústria que opera a secagem dos grãos produzidos na região de Guarapuava em consumir áreas de florestas plantadas de eucalipto voltadas à produção de madeira com fins energéticos. Para tanto, buscou-se identificar a produtividade dos plantios florestais de eucalipto, estabelecer uma relação de produção de grãos e consumo de madeira para a secagem e elaborar projeções para a quantidade de madeira energética consumida na secagem de grãos produzidos na região do estudo.

\section{MATERIAL E MÉTODOS}

A pesquisa caracterizou-se pela sua natureza aplicada, pois visou gerar conhecimentos para a aplicação prática. Ela teve um enfoque quantitativo, por confiar e basear-se em dados numéricos e esquemas dedutivos no alcance dos objetivos, e por um caráter explicativo, uma vez que buscava entender as causas dos eventos (SILVA; MENEZES, 2001; SAMPIERI et al., 2006).

A região do estudo contempla os municípios inclusos no núcleo administrativo da Secretaria da Agricultura e Abastecimento do Estado do Paraná, a saber: Campina do Simão, Candói, Cantagalo, Foz do Jordão, Goioxim, Guarapuava, Laranjal, Palmital, Pinhão, Prudentópolis, Reserva do Iguaçu e Turvo. Esses municípios somam $14.032 \mathrm{~km}^{2}$, o que representa $7 \%$ de todo o território paranaense e $67 \%$ dos $21.093 \mathrm{~km}^{2}$ da região centro-sul do estado.

O referencial teórico utilizado no presente estudo está fundamentado nos princípios de cadeias produtivas e de demanda derivada. As cadeias produtivas podem ser entendidas como um conjunto de componentes interativos que inclui os sistemas de produção, os fornecedores de serviços e insumos, as indústrias de processamento e transformação, as redes de comércio (atacado e varejo) e o consumidor final (CASTRO et al., 1996). Associados aos componentes das cadeias encontram-se o ambiente institucional (conjunto de normas e leis que regulam as transações físico-financeiras) e o organizacional (instituições de governo, crédito, pesquisa etc.), que, juntos, exercem influência sobre o desempenho dos elementos que compõem as cadeias produtivas (CASTRO et al., 2002).

Pindyck e Rubinfeld (2002) explicam que a demanda derivada representa a demanda por um insumo que depende e é derivada simultaneamente do nível de produção da empresa e dos custos dos 
insumos. Nesse sentido, Besanko e Braeutigam (2004) esclarecem que a demanda de um bem é derivada da produção e da venda de outros bens. Sendo assim, para fins deste estudo, entende-se que a quantidade de madeira com fins energéticos consumida na secagem de grãos é derivada e diretamente proporcional à produção de grãos na região, uma vez que esse insumo faz-se necessário ao processo de secagem dos grãos produzidos.

Quanto ao procedimento operacional adotado na avaliação a que se propõe esta pesquisa, optouse pela revisão bibliográfica na identificação da produtividade das florestas de eucalipto com fins energéticos plantadas na região de Guarapuava.

A relação entre a produção de grãos e a quantidade de madeira necessária no processo de secagem desses grãos foi estabelecida com base em informações primárias coletadas nas agroindústrias que operavam a secagem dos grãos na região do estudo, mediante comunicação pessoal, entre os dias 03 e 28 de outubro de 2011.

As projeções para a quantidade de madeira para fins energéticos consumida na secagem de grãos produzidos na região do estudo foram elaboradas mediante um procedimento dividido em duas etapas, as quais se destacam pelo seu caráter exploratório. A primeira etapa consistiu em elaborar projeções para a produção dos grãos cultivados na região, com base nas tendências formadas para o agronegócio paranaense, fornecidas pela Assessoria de Gestão Estratégica do Ministério da Agricultura, Pecuária e Abastecimento (MAPA), para o período de 2012 a $2022^{1}$.

Assim como em relatórios anteriores do MAPA (2011), as tendências apresentadas pela Assessoria de Gestão Estratégica variavam entre dois valores limites (inferior e superior), que representavam o grau de incerteza das previsões, o que possibilitou a elaboração de 3 diferentes linhas de projeção para um mesmo produto, referentes ao limite inferior, ao superior e à média entre eles. Assumiuse, também, que a produção de grãos na região de Guarapuava tivesse comportamento similar à estadual. Nas situações em que não foram encontrados parâmetros para a elaboração das projeções de produção de determinado grão, foi levada em consideração a expectativa das empresas produtoras, resguardadas pela opinião de especialistas. Sendo assim, a etapa inicial consistiu em aplicarem-se as tendências (médias, inferiores e superiores) de crescimento identificadas para os diferentes grãos cultivados em Guarapuava e região às suas respectivas produções.

$\mathrm{Na}$ segunda etapa do procedimento metodológico, aplicaram-se às projeções de produção dos grãos cultivados na região de estudo os coeficientes técnicos identificados para os grãos, procedimento sustentado no conceito de demanda derivada e que fornece o consumo potencial de madeira energética na secagem dos grãos produzidos na região de Guarapuava, em três diferentes visões sobre o futuro.

As previsões que fundamentaram as projeções elaboradas neste estudo trabalhavam com uma base de dados de 34 períodos (1977-2011) e três modelos estatísticos: Suavização Exponencial, Box \& Jenkins (Arima) e Modelo de Espaço de Estados. Segundo MAPA (2011). Entre os três, a tendência é de selecionar o modelo mais conservador e não aqueles que indicam taxas arrojadas de crescimento. Além disso, são consideradas também a coerência dos resultados obtidos, comparações internacionais dos dados de produção, a tendência passada e o potencial de crescimento e a opinião de especialistas de instituições públicas (MAPA, Escola Superior de Agricultura "Luiz de Queiroz" (ESALQ), Companhia Nacional de Abastecimento (CONAB), Universidade Federal de Viçosa (UFV) e EMBRAPA, entre outras) e privadas. Para as produções de milho, trigo e soja, foram considerados os resultados do Modelo de Espaço de Estados, um modelo estatístico para séries temporais multivariadas estacionárias, conhecido como representação markoviana e que sintetiza os valores do presente e passado para predição de valores futuros com base em séries temporais relevantes (MAPA, 2011).

Aplicando-se os coeficientes técnicos de secagem identificados para os grãos de milho, soja, trigo e cevada às suas respectivas projeções de produção na área de estudo para o período de 2012 a 2022, os resultados levam à configuração do panorama de consumo potencial de madeira com fins energéticos para a região estudada.

Rodigheri et al. (2007) ressaltam que, normalmente, na região de Guarapuava, os plantios florestais de eucalipto voltados à produção de madeira com fins energéticos passam por três ciclos de corte raso, aos 7, 14 e 21 anos de idade. Em média, os plantios de até 7 anos de idade apresentam

\footnotetext{
${ }^{1}$ Informação verbal fornecida por J. G. GASQUES, da Assessoria de Gestão Estratégica do Ministério da Agricultura, Pecuária e
} Abastecimento (MAPA). 
produtividade de $40 \mathrm{~m}^{3} /$ hectare por ano, resultando numa produção de $280 \mathrm{~m} / \mathrm{ha}$, enquanto os plantios de 14 e 21 anos de idade, por serem resultado do manejo de brotações, apresentam produtividade média de $35 \mathrm{~m}^{3} / \mathrm{ha}$ por ano, ou seja, produção de $245 \mathrm{~m}^{3} / \mathrm{ha}$.

\section{RESULTADOS E DISCUSSÃO}

As informações coletadas permitiram verificar que somente os grãos de milho, soja, trigo e cevada passavam por processos de secagem na região de Guarapuava e que o consumo de madeira de eucalipto na secagem de milho era de $0,0574 \mathrm{~m}^{3} / \mathrm{t}$, de $0,0218 \mathrm{~m}^{3} / \mathrm{t}$ na secagem de soja, de $0,0224 \mathrm{~m}^{3} / \mathrm{t}$ na secagem de trigo e de $0,0258 \mathrm{~m}^{3} / \mathrm{t}$ na secagem de cevada. Para o milho, considerou-se que, ao entrar no silo de secagem, o teor de umidade médio era de $21 \%$, o final desejado era de $14 \%$ e o consumo de madeira era de $0,0082 \mathrm{~m}^{3}$ para cada $\%$ de teor de umidade reduzido. Para a soja, foi considerado um teor de umidade inicial médio de $16 \%$, o final de $14 \%$ e o consumo de madeira de $0,0109 \mathrm{~m}^{3} / \%$ de teor de umidade. Para o trigo, o teor de umidade inicial médio considerado foi de $16,5 \%$, o final desejado de $13 \%$ e o consumo de $0,0064 \mathrm{~m}^{3}$ de madeira por \% de teor de umidade. Para os grãos de cevada, o teor de umidade inicial média estipulado foi de $16 \%$, o final de $13 \%$ e o consumo de madeira de $0,0086 \mathrm{~m}^{3} / \%$ de teor de umidade.

Sobre esses resultados, ressalte-se a discrepância dos encontrados por Afonso Júnior et al. (2006), que estimou a quantidade de madeira de eucalipto necessária na secagem de 1 tonelada de grãos de milho e soja. Esses pesquisadores estimaram que se consome $0,25 \mathrm{~m}^{3}$ por tonelada seca de grãos de milho seco e $0,17 \mathrm{~m}^{3}$ para cada tonelada seca de soja.

Possivelmente, a diferença ocorra em função dos diferentes teores de umidade inicial e final e da eficiência térmica do equipamento de secagem considerado. Para o milho, Afonso Júnior et al. (2006) levaram em consideração para as estimativas um teor de umidade inicial de $25 \%$ e final de $13 \%$, e para a soja, um teor de umidade inicial de $20 \%$ e final de $11 \%$. Outra possível razão para a diferença entre os resultados das pesquisas pode estar relacionada ao fato de que, em Afonso Júnior et al. (2006), a eficiência térmica dos equipamentos usados na secagem dos grãos era de 40\%, referente a um estudo de 1980.

As projeções para a produção de grãos da região do estudo foram realizadas para grãos de milho, soja, trigo e cevada, pois eram os que passavam pelo processo de secagem.

A tabela 1 apresenta a projeção regional para a produção de milho de 2012 a 2022.

Tabela 1. Projeções da produção de milho na área de estudo de 2012 e 2022.

Table 1. Projections of maize production in the focused area from 2012 to 2022.

\begin{tabular}{lccc}
\hline \multirow{2}{*}{ Safra } & \multicolumn{3}{c}{ Produção estimada (toneladas) } \\
\cline { 2 - 4 } & Média & Limite inferior & Limite superior \\
\hline 2012 & 831.750 & 613.747 & 1.049 .753 \\
2013 & 792.658 & 525.099 & 1.060 .217 \\
2014 & 833.715 & 513.050 & 1.154 .379 \\
2015 & 830.380 & 471.837 & 1.188 .923 \\
2016 & 851.598 & 455.596 & 1.247 .600 \\
2017 & 865.088 & 442.564 & 1.287 .613 \\
2018 & 874.322 & 414.928 & 1.333 .716 \\
2019 & 885.258 & 397.246 & 1.373 .270 \\
2020 & 898.552 & 383.363 & 1.413 .742 \\
2021 & 910.537 & 369.611 & 1.451 .462 \\
2022 & 923.241 & 357.692 & 1.488 .790 \\
\hline
\end{tabular}

A previsão era de que a produção média de milho na área de estudo ao final do período analisado apresentasse crescimento aproximado de $11 \%$ em relação ao início do período e variasse entre 357.692 e 1.488.790 toneladas, resultado que reflete o grau de incerteza associado às previsões fornecidas pela Assessoria de Gestão Estratégica.

A tabela 2 apresenta as projeções e tendências da produção de milho no estado do Paraná.

Admite-se o pressuposto de que a produção regional desse grão apresenta comportamento similar à produção estadual, conforme ilustra a figura 1. Possivelmente, a similaridade seja um reflexo da fraca 
participação regional na produção estadual $(5,52 \%$ em 2011). A produção regional acaba apenas evidenciando as condições de mercado, favoráveis ou não. A mesma situação ocorre para as produções de soja e trigo, nas quais a participação regional das produções estaduais é de 4,63\% e 5,96\%, respectivamente.

Tabela 2. Projeções e tendências da produção de milho no estado do Paraná de 2012 a 2022.

Table 2. Projections and trends on maize production in the state of Paraná from 2012 to 2022.

\begin{tabular}{|c|c|c|c|c|c|}
\hline \multirow{2}{*}{ Safra } & \multicolumn{3}{|c|}{ Produção (mil toneladas) } & \multirow{2}{*}{$\begin{array}{c}\text { Tendência } \\
\text { identificada }(\%)\end{array}$} & \multirow{2}{*}{$\begin{array}{l}\text { Variação dos limites em } \\
\text { relação à média }(\%)\end{array}$} \\
\hline & Média & Lim. inf. & Lim. sup. & & \\
\hline 2012 & 12.705 & 9.374 & 16.035 & & $\pm 26,2$ \\
\hline 2013 & 12.105 & 8.018 & 16.191 & $-4,7$ & $\pm 33,8$ \\
\hline 2014 & 12.732 & 7.836 & 17.629 & 5,2 & $\pm 38,5$ \\
\hline 2015 & 12.680 & 7.205 & 18.155 & $-0,4$ & $\pm 43,2$ \\
\hline 2016 & 13.004 & 6.957 & 19.051 & 2,6 & $\pm 46,5$ \\
\hline 2017 & 13.210 & 6.578 & 19.662 & 1,6 & $\pm 48,8$ \\
\hline 2018 & 13.351 & 6.336 & 20.366 & 1,1 & $\pm 52,5$ \\
\hline 2019 & 13.518 & 6.067 & 20.970 & 1,3 & $\pm 55,1$ \\
\hline 2020 & 13.721 & 5.854 & 21.588 & 1,5 & $\pm 57,3$ \\
\hline 2021 & 13.904 & 5.644 & 22.164 & 1,3 & $\pm 59,4$ \\
\hline 2022 & 14.098 & 5.462 & 22.734 & 1,4 & $\pm 61,3$ \\
\hline
\end{tabular}

Fonte: Assessoria de Gestão Estratégica' ${ }^{1}$. Elaborada pelos autores.
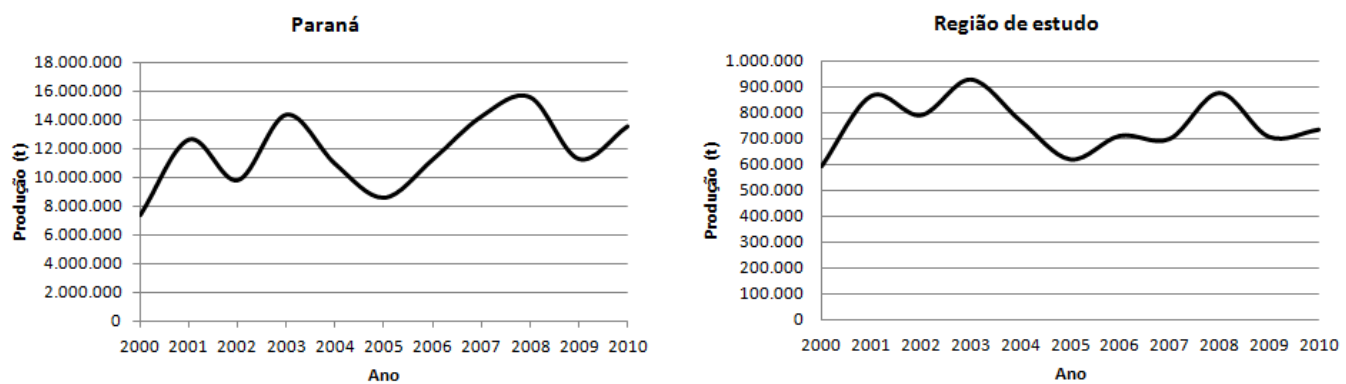

Figura 1. Comportamento das produções de milho do Paraná e da área de estudo.

Figure 1. Behavior of the maize production of Paraná and the focused area.

Fonte: Instituto Paranaense de Desenvolvimento Econômico e Social (IPARDES) (2011), adaptado pelo autor.

A tabela 3 apresenta a projeção regional para a produção de soja de 2012 a 2022.

Tabela 3. Projeções da produção de soja na área de estudo de 2012 a 2022.

Table 3. Projections of soybean production in the focused area from 2012 to 2022.

\begin{tabular}{lccc}
\hline \multirow{2}{*}{ Safra } & \multicolumn{3}{c}{ Produção estimada (toneladas) } \\
\cline { 2 - 4 } & Média & Limite inferior & Limite superior \\
\hline 2012 & 677.090 & 565.370 & 788.810 \\
2013 & 687.158 & 548.352 & 825.964 \\
2014 & 701.056 & 533.503 & 868.608 \\
2015 & 713.629 & 523.090 & 904.168 \\
2016 & 726.629 & 514.453 & 938.804 \\
2017 & 739.486 & 508.766 & 970.205 \\
2018 & 752.391 & 504.102 & 1.000 .679 \\
2019 & 765.248 & 500.472 & 1.030 .024 \\
2020 & 778.152 & 498.018 & 1.058 .287 \\
2021 & 791.057 & 495.993 & 1.086 .121 \\
2022 & 803.962 & 495.240 & 1.112 .683 \\
\hline
\end{tabular}


A expectativa era que a produção de soja na região estudada atingisse um total de 803.962 toneladas, podendo variar entre 495.240 e 1.113 .683 toneladas em 2022 , crescimento de $18,7 \%$ em relação ao início do período.

A tabela 4 apresenta as projeções para a produção de soja no estado do Paraná.

Tabela 4. Projeções e tendências da produção de soja no estado do Paraná de 2012 a 2022.

Table 4. Projections and trends on soybean production in the state of Paraná from 2012 to 2022.

\begin{tabular}{lccccc}
\hline \multirow{2}{*}{ Safra } & \multicolumn{3}{c}{ Produção (mil toneladas) } & Tendência da & $\begin{array}{c}\text { Variação dos limites em } \\
\text { relação à projeção }(\%)\end{array}$ \\
\cline { 2 - 4 } & Projeção & Lim. inf. & Lim. sup. & projon & \\
\hline 2012 & 14.324 & 11.962 & 16.687 & & $\pm 16,5$ \\
2013 & 14.537 & 11.602 & 17.472 & 1,5 & $\pm 20,2$ \\
2014 & 14.831 & 11.280 & 18.382 & 2,0 & $\pm 23,9$ \\
2015 & 15.097 & 11.061 & 19.132 & 1,8 & $\pm 26,7$ \\
2016 & 15.372 & 10.891 & 19.853 & 1,8 & $\pm 29,2$ \\
2017 & 15.644 & 10.762 & 20.526 & 1,8 & $\pm 31,2$ \\
2018 & 15.917 & 10.663 & 21.171 & 1,7 & $\pm 33,0$ \\
2019 & 16.189 & 10.589 & 21.790 & 1,7 & $\pm 34,6$ \\
2020 & 16.462 & 10.535 & 22.390 & 1,7 & $\pm 36,0$ \\
2021 & 16.735 & 10.498 & 22.972 & 1,7 & $\pm 37,3$ \\
2022 & 17.008 & 10.476 & 23.539 & 1,6 & $\pm 38,4$ \\
\hline
\end{tabular}

Fonte: Assessoria de Gestão Estratégica ${ }^{1}$. Adaptada pelos autores.

Nas projeções da soja na região de estudo, também foram consideradas as tendências de crescimento e variações de limites encontradas nas previsões da produção de soja do estado do Paraná.

Nota-se que, para esse grão, a produção da região de estudo também apresenta comportamento parecido à estadual: períodos de aumentos e quedas nas produções de ambas ocorreram nos mesmos anos, conforme ilustra a figura 2 .

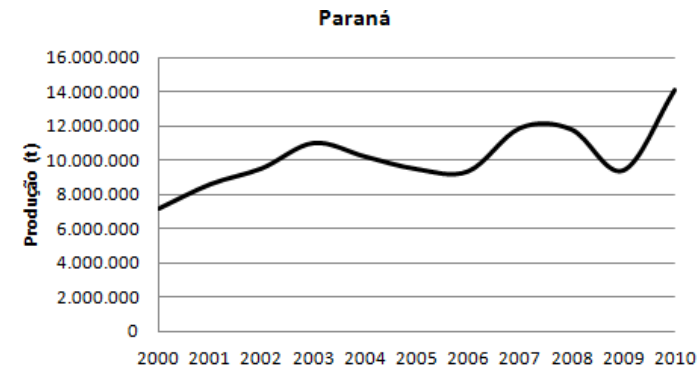

Ano

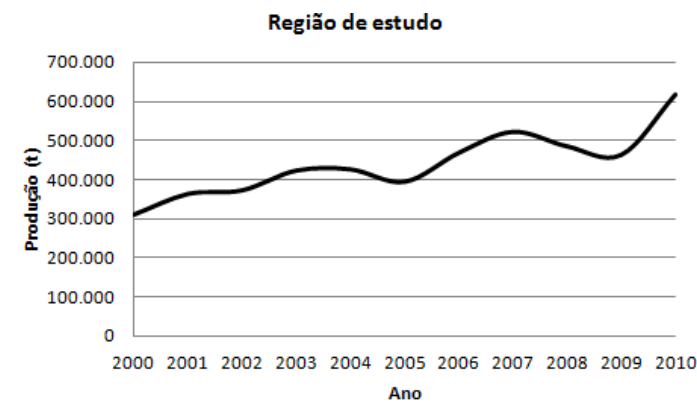

Ano

Figura 2. Comportamento das produções de soja do Paraná e da área de estudo.

Figure 2. Behavior of soybean production in the State of Paraná and the focused area.

Fonte: IPARDES (2011), adaptado pelos autores.

O resultado das projeções de trigo na região estudada é apresentado na tabela 5.

Para o grão de trigo, as estimavas indicaram que, no ano de 2022 , seriam produzidas 173.731 toneladas, valor $17,6 \%$ superior em relação ao início do período analisado. A quantidade média ainda poderia variar entre 40.742 e 306.683 toneladas.

A tabela 6 apresenta as projeções e tendências da produção de trigo.

Assim como nos casos da soja e milho, a produção de trigo da área de estudo foi estimada com base nas tendências das previsões e variação dos limites identificados nas previsões para a produção paranaense de trigo. 
Tabela 5. Projeções da produção de trigo na área de estudo de 2012 a 2022.

Table 5. Projections of wheat production on the focused area from 2012 to 2022.

\begin{tabular}{lccc}
\hline \multirow{2}{*}{ Safra } & \multicolumn{3}{c}{ Produção estimada (toneladas) } \\
\cline { 2 - 4 } 2012 & Média & Limite inferior & Limite superior \\
2013 & 147.765 & 85.309 & 210.221 \\
2014 & 149.813 & 74.201 & 225.426 \\
2015 & 151.908 & 66.872 & 236.943 \\
2016 & 154.366 & 61.592 & 247.140 \\
2017 & 156.960 & 57.267 & 256.654 \\
2018 & 159.692 & 53.716 & 265.667 \\
2019 & 162.423 & 50.484 & 274.362 \\
2020 & 165.246 & 52.259 & 278.232 \\
2021 & 168.068 & 45.158 & 290.978 \\
2022 & 170.890 & 42.882 & 298.899 \\
\hline
\end{tabular}

Tabela 6. Projeções e tendências da produção de trigo no estado do Paraná de 2012 a 2022.

Table 6. Projections and trends on wheat production in the state of Paraná from 2012 to 2022.

\begin{tabular}{cccccc}
\hline \multirow{2}{*}{ Safra } & \multicolumn{3}{c}{ Produção (mil toneladas) } & \multirow{2}{*}{$\begin{array}{c}\text { Tendência da } \\
\text { projeção }(\%)\end{array}$} & $\begin{array}{c}\text { Variação dos limites em } \\
\text { relação à projeção }(\%)\end{array}$ \\
\cline { 2 - 4 } & Projeção & Lim. inf. & Lim. sup. & 1,4 & $\pm 42,3$ \\
2012 & 3.246 & 1.874 & 4.618 & 1,4 & $\pm 50,5$ \\
2013 & 3.291 & 1.630 & 4.952 & 1,4 & $\pm 56,0$ \\
2014 & 3.337 & 1.469 & 5.205 & 1,6 & $\pm 60,1$ \\
2016 & 3.391 & 1.353 & 5.429 & 1,7 & $\pm 63,5$ \\
2017 & 3.448 & 1.259 & 5.638 & 1,7 & $\pm 66,4$ \\
2018 & 3.508 & 1.179 & 5.836 & 1,7 & $\pm 68,9$ \\
2019 & 3.568 & 1.110 & 6.027 & 1,7 & $\pm 68,4$ \\
2020 & 3.630 & 1.048 & 6.112 & 1,7 & $\pm 73,1$ \\
2021 & 3.692 & 992 & 6.392 & 1,7 & $\pm 74,9$ \\
2022 & 3.754 & 941 & 6.566 & 1,7 & $\pm 76,5$ \\
\hline
\end{tabular}

Fonte: Assessoria de Gestão Estratégica ${ }^{1}$. Adaptada pelos autores.

Releve-se ainda que, no período de 2000 a 2010, a produção regional não foi similar em todos os anos, somente a partir do ano de 2002 os períodos de queda e aumento na produção foram os mesmos.

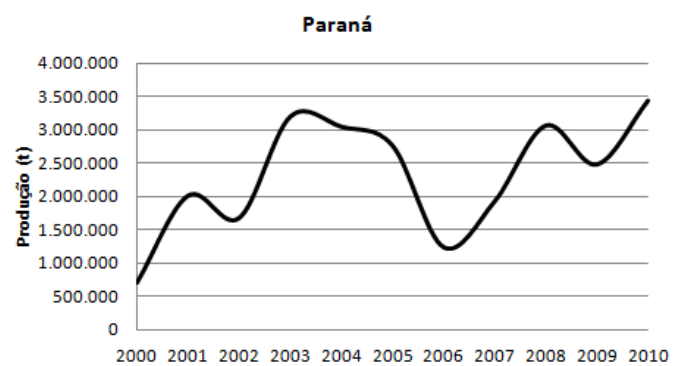

Ano

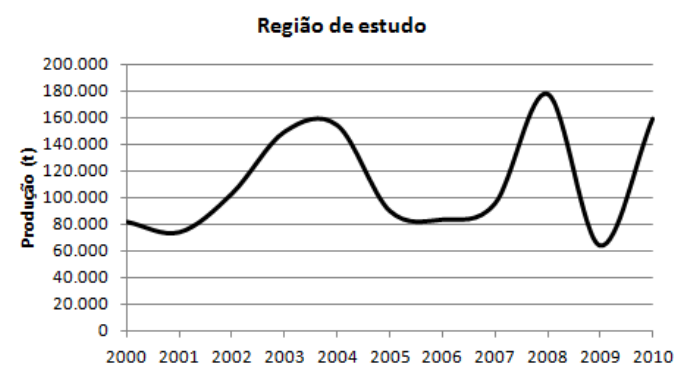

Ano

Figura 3. Comportamento das produções de trigo do Paraná e da área de estudo.

Figure 3. Behavior of wheat production in the State of Paraná and the focused area.

Fonte: IPARDES (2011), adaptado pelos autores.

A tabela 7 mostra os resultados das projeções para a produção de cevada na região estudada. 
Os resultados indicaram que a produção de cevada na área de estudo deveria chegar às 211.774 toneladas em 2022, incremento de $62 \%$ em relação ao início do período, podendo variar entre 201.186 e 222.363 toneladas.

A cevada foi o único produto para o qual não foram encontradas projeções oficiais de produção, de forma que as projeções foram formadas com base em informações fornecidas pela Fundação Agrária de Pesquisa Agropecuária (FAPA), entidade vinculada à Cooperativa Agrária, maior produtora de cevada da região de Guarapuava (informação verbal).

Segundo as informações obtidas, para o período de 2012 a 2022, esperava-se que a produção de cevada na área de estudo apresentasse crescimento de 5\% ao ano, podendo variar entre $\pm 5 \%$, com base fundamentalmente em ganhos de produtividade ${ }^{2}$. Adicione-se que os dados foram considerados bastante plausíveis, ressaltando que poderiam ser utilizados na pesquisa (informação pessoal) ${ }^{3}$. Em razão das tendências terem sido estipuladas diretamente para a região, não foi necessário validar a pressuposição de que a produção de cevada da região estudada tinha comportamento similar à estadual.

Tabela 7. Projeções da produção de cevada na área de estudo de 2012 a 2022.

Table 7. Projections of barley production on the focused area from 2012 to 2022.

\begin{tabular}{|c|c|c|c|c|c|}
\hline \multirow[b]{2}{*}{ Safra } & \multicolumn{3}{|c|}{ Produção (toneladas) } & \multirow{2}{*}{$\begin{array}{c}\text { Tendência da } \\
\text { projeção }\end{array}$} & \multirow{2}{*}{$\begin{array}{l}\text { Variação dos limites em } \\
\text { relação à projeção }(\%)\end{array}$} \\
\hline & Média & $\begin{array}{c}\text { Limite } \\
\text { inferior }\end{array}$ & $\begin{array}{c}\text { Limite } \\
\text { superior }\end{array}$ & & \\
\hline 2012 & 130.011 & 123.510 & 136.512 & & \\
\hline 2013 & 136.512 & 129.686 & 143.337 & & \\
\hline 2014 & 143.337 & 136.170 & 150.504 & & \\
\hline 2015 & 150.504 & 142.979 & 158.029 & & \\
\hline 2016 & 158.029 & 150.128 & 165.931 & & \\
\hline 2017 & 165.931 & 157.634 & 174.227 & $5 \%$ ao ano & $\pm 5 \%$ \\
\hline 2018 & 174.227 & 165.516 & 182.939 & & \\
\hline 2019 & 182.939 & 173.792 & 192.085 & & \\
\hline 2020 & 192.085 & 182.481 & 201.690 & & \\
\hline 2021 & 201.690 & 191.605 & 211.774 & & \\
\hline 2022 & 211.774 & 201.186 & 222.363 & & \\
\hline
\end{tabular}

A tabela 8 apresenta o panorama de consumo potencial de madeira com fins energéticos para a região estudada.

Tabela 8. Panorama de consumo potencial de madeira com fins energéticos na secagem de grãos na área de estudo de 2012 a 2022.

Table 8. Overview of potential consumption of wood for energy purposes in grain drying on the focused area from 2012 to 2022.

\begin{tabular}{lccc}
\hline Safra & Quantidade média $\left(\mathbf{m}^{\mathbf{3}}\right)$ & Quantidade inferior $\left(\mathbf{m}^{\mathbf{3}}\right)$ & Quantidade superior $\left(\mathbf{m}^{\mathbf{3}}\right)$ \\
\hline 2012 & 69.167 & 52.652 & 85.683 \\
2013 & 67.356 & 47.103 & 87.610 \\
2014 & 70.239 & 46.091 & 94.388 \\
2015 & 70.562 & 43.555 & 97.568 \\
2016 & 72.315 & 42.522 & 102.108 \\
2017 & 73.635 & 41.764 & 105.505 \\
2018 & 74.722 & 40.207 & 109.236 \\
2019 & 75.918 & 39.367 & 112.468 \\
2020 & 77.261 & 38.581 & 115.941 \\
2021 & 78.541 & 37.932 & 119.150 \\
2022 & 79.875 & 37.431 & 122.320 \\
\hline
\end{tabular}

${ }^{2}$ Informação fornecida por C. U. CHAVES, da Fundação Agrária de Pesquisa Agropecuária.

${ }^{3}$ Informação fornecida por E. MINELLA, pesquisador da EMBRAPA Trigo. 
Os resultados apontam para um crescimento de $1,4 \%$ ao ano para o consumo potencial de madeira com fins energéticos no processo de secagem dos grãos de milho, soja, trigo e cevada produzidos na área de estudo, considerando-se o período de 2012 a 2022.

Ressalte-se que a "quantidade média" refere-se às quantidades de madeira necessárias para secar as produções de milho, soja, trigo e cevada caso fossem confirmadas as projeções médias elaboradas para a produção de cada um desses produtos e considerados os coeficientes técnicos de secagem. A "quantidade inferior" associa-se às quantidades de madeira requisitadas na secagem das produções de milho, soja, trigo e cevada se as projeções dos limites inferiores fossem confirmadas. Da mesma forma, a "quantidade superior" vincula-se às quantidades de madeira indispensáveis no processo de secagem das produções desses grãos se, por ventura, as projeções dos limites superiores se confirmassem.

Considerando a produtividade média de $40 \mathrm{~m}^{3} / \mathrm{ha}$ por ano dos plantios florestais de eucalipto com fins energéticos na área de estudo e o panorama de consumo potencial de madeira com fins energéticos da tabela 8 , a capacidade potencial da indústria que opera a secagem dos grãos de milho, soja, trigo e cevada na região de Guarapuava em consumir áreas de florestas plantadas de eucalipto voltadas à produção de madeira energética é ilustrada na tabela 9.

Tabela 9. Consumo potencial de áreas de florestas plantadas de eucalipto com fins energéticos para a secagem dos grãos de milho, soja, trigo e cevada na área de estudo entre 2012 e 2022.

Table 9. Potential consumption of eucalyptus planted areas for energy purposes for drying of maize, soybean, wheat and barley in the focused area between 2012 and 2022.

\begin{tabular}{lccc}
\hline \multirow{2}{*}{ Ano } & \multicolumn{3}{c}{ Consumo de florestas de eucalipto (ha) } \\
\cline { 2 - 4 } & Médio & Inferior & Superior \\
\hline 2012 & 288,2 & 219,4 & 357,0 \\
2013 & 280,7 & 196,3 & 365,0 \\
2014 & 292,7 & 192,0 & 393,3 \\
2015 & 294,0 & 181,5 & 406,5 \\
2016 & 301,3 & 177,2 & 425,5 \\
2017 & 306,8 & 174,0 & 439,6 \\
2018 & 311,3 & 167,5 & 455,2 \\
2019 & 316,3 & 164,0 & 468,6 \\
2020 & 321,9 & 160,8 & 483,1 \\
2021 & 327,3 & 158,1 & 496,5 \\
2022 & 332,8 & 156,0 & 509,7 \\
\hline Total & 3373,3 & 1946,7 & 4799,9 \\
\hline Média & 306,7 & 177,0 & 436,4 \\
\hline
\end{tabular}

Observa-se que o consumo médio de florestas de eucalipto voltadas para a produção de madeira com fins energéticos reflete a relação entre a produtividade dessas florestas e a quantidade média dentro do panorama de consumo potencial de madeira com fins energéticos na secagem de grãos de milho, soja, trigo e cevada na área de estudo. O consumo inferior de áreas florestais é resultado da associação da produtividade das florestas de eucalipto na região com as quantidades inferiores de consumo potencial de madeira estimado na tabela 8 . O consumo superior de áreas do tipo de floresta considerada no estudo está relacionado à capacidade de produção de madeira nessas florestas e à quantidade superior de consumo potencial de madeira projetado no estudo.

Nota-se ainda que a capacidade da indústria que opera a secagem dos grãos de milho, soja, trigo e cevada na região de Guarapuava em consumir áreas de florestas de eucalipto poderá variar entre 1.947 e 4.800 ha, no período de 2012 a 2022. Dependendo do cenário que venha a se concretizar, essa indústria deve se preparar para comprar ou deixar apta ao corte uma área média anual de florestas de eucalipto com produtividade média de $40 \mathrm{~m}$ 3/ha por ano, que pode variar entre 177,0 e 436,4 ha. Atente-se ao fato de que essas variações de consumo ilustram a incerteza das previsões realizadas e que o método utilizado na pesquisa não prevê de nenhuma forma alterações nos coeficientes técnicos de secagem de grãos quanto ao 
consumo de madeira de eucalipto, aumentos da produtividade dos plantios desse gênero florestal e o uso de outros combustíveis no processo de secagem dos grãos.

\section{CONCLUSÕES}

- A região de Guarapuava, segundo os cenários analisados, caracteriza-se por um alto e variado consumo potencial de madeira com fins energéticos, destinado ao abastecimento pleno do processo de secagem dos grãos de milho, soja, trigo e cevada produzidos.

- É recomendável que se programe a integração dos plantios florestais de eucalipto nas cadeias produtivas de grãos, entre outras, para que o processo de secagem não venha a sofrer com a falta desse combustível e não seja requerida a compra de madeira voltada à produção de energia num contexto de um mercado oligopolizado, como tem sido caracterizado o de base florestal.

- Igualmente importante é a realização de um inventário visando estimar o volume das florestas potencialmente destinadas à geração de energia e o equilíbrio entre a produção e o consumo de madeira decorrente dos processos de secagem de grãos na região estudada.

\section{REFERÊNCIAS}

AFONSO JÚNIOR, P. C.; OLIVEIRA FILHO, D.; COSTA, D. R. Viabilidade econômica de produção de lenha de eucalipto para secagem de produtos agrícolas. Revista Engenharia Agrícola, Jaboticabal, v. 26, n. 1 , p. $28-35,2006$.

BESANKO, D.; BRAEUTIGAM, R. R. Microeconomia: uma abordagem completa. Rio de Janeiro: Editora LTC, 2004. $610 \mathrm{p}$.

BITTENCOURT, L. P.; OLIVEIRA, G. B. A indústria madeireira paranaense nos anos recentes. Revista das Faculdades Santa Cruz, v. 7, n. 1, p. 33 - 41, 2009. Disponível em: <http://www.santacruz.br/v3/ revistaacademica/12/cap4.pdf>. Acesso em: 29/10/2011.

BRASIL. Agência Nacional de Energia Elétrica - ANEEL. Atlas de energia elétrica do Brasil. Brasília: ANEEL, 2005. 2 ed. 243 p.

. Atlas de energia elétrica do Brasil. Brasília: ANEEL, 2008. 3 ed. 236 p.

BUAINAin, A. M.; BATAlHA, M. O. Cadeia produtiva de madeira. Série Agronegócio. Brasília: Ministério da Agricultura, Pecuária e Abastecimento, 2007. v. 6. Disponível em: $<$ http://www.iica.org.br/Docs/CadeiasProdutivas/Cadeia\%20Produtiva\%20de\%20Florestas\%20Plantadas $\% 20 \mathrm{e} \% 20$ Madeira.pdf $>$. Acesso em: 12/12/2011.

CASTRO, A. M. G. de; LIMA, S. M. V.; CRISTO, C. M. P. N. Cadeia produtiva: marco conceitual para apoiar a prospecção tecnológica. In: XXII Simpósio de Gestão da Inovação Tecnológica, 2002, Salvador. Disponível em: <http://www.mdic.gov.br/arquivos/dwnl_1197031881.pdf〉. Acesso em: 09/10/2011.

CASTRO, A. M. G. de; JOHNSON, B. B.; PAEZ, M. L. D.; FREITAS FILHO, A. Análise prospectiva de cadeias produtivas agropecuárias. $1996,18 \mathrm{p}$. Disponível em: <http://www.gestaoct.org.br/ forum_municipal/apresent/cd_anton_maria/anal_prospectiva_cp_agropec.pdf $>$. Acesso em: 02/08/2011.

GODINHO, C. H. W. Valor bruto da produção agrícola paranaense em 2010. Curitiba: Secretaria de Agricultura e Abastecimento do Estado do Paraná, 2011. 3 p. Disponível em: <http://www.agricultura.pr. gov.br/arquivos/File/deral/analise1002.pdf >. Acesso em: 10/12/2011.

INSTITUTO PARANAENSE DE DESENVOLVIMENTO ECONÔMICO E SOCIAL (IPARDES). Banco de dados. Base de Dados do Estado - BDEweb. Disponível em: <http://ipardes.pr.gov.br/imp/ index.php>. Acesso em: 08/10/2011.

MENDES JÚNIOR, C. L. M.; NASCIMENTO, F. A. F.; FIALHO, J. T.; CEMIN, L. G.; SCHAITZA, E.; GONÇALVES, R. V. Demanda de madeira para secagem de produtos agrícolas no Paraná. Curitiba: Secretaria de Agricultura e Abastecimento do Estado do Paraná, 2011. 1 p. Texto técnico. Disponível em: 
<http://www.agricultura.pr.gov.br/arquivos/File/Florestais/Textos_tecnicos/madeiraparasecagem.pdf>. Acesso em: 10/12/2011.

MINISTÉRIO DA AGRICULTURA, PECUÁRIA E ABASTECIMENTO (MAPA). Brasil Projeções do Agronegócio 2010/2011 a 2020/2012. Brasília: MAPA, 2011. 59 p.

NOVAKOVSKI, L.; FAJARDO, S. O transporte ferroviário de pinus em Guarapuava, PR. Revista Eletrônica Lato Sensu, Unicentro, v. 6, p. 1 - 14, 2008. Disponível em: <http://web03.unicentro.br /especializacao/Revista_Pos/P\%C3\%A1ginas/6\%20Edi\%C3\%A7\%C3\%A3o/Aplicadas/PDF/17-

Ed6_CS-Trans.pdf>. Acesso em: 12/12/2011.

PINDYCK, R. S.; RUBINFELD, D. L. Microeconomia. São Paulo: Prentice Hall, 2002. 5 ed. 711 p.

POLZL, P. F. K. Análise da produtividade em fábricas de painéis compensados plastificados. $90 \mathrm{f}$. Dissertação (Mestrado em Engenharia de Produção) - Universidade Tecnológica Federal do Paraná, Ponta Grossa, 2011.

RIBAS, A, J. F. A cadeia produtiva da madeira no município de Guarapuava. 91 f. Dissertação (Mestrado em Desenvolvimento Econômico) - Universidade Federal do Paraná, Curitiba, 2009.

RODIGHERI, H. R.; SILVA, H. D.; TUSSOLINI, E. L. Indicadores de custos, produtividade e renda de plantios de eucaliptos para energia na região de Guarapuava, PR. Comunicado Técnico 179. Colombo: Embrapa, 2007.

SAMPIERI, R. H.; COLLADO, C. F.; LUCIO, P. B. Metodologia de pesquisa. São Paulo: McGrawHill, 2006. 3 ed. 583 p.

SILVA, E. L.; MENEZES, E. M. Metodologia da pesquisa e elaboração de dissertação. Florianópolis: Laboratório de Ensino a Distância da UFSC, 2001. 3 ed. 121 p.

TEIXEIRA, T. V. R. Uso da madeira e derivados para energia no Estado do Paraná. $50 \mathrm{f}$. Monografia (Engenharia Industrial Madeireira) - Universidade Federal do Paraná, Curitiba, 2009. 
